Jurnal Media Analis Kesehatan, Vol. 9, No.2, November 2018

http://journal.poltekkes-mks.ac.id/ojs2/index.php/mediaanalis

e-ISSN : 2621-9557

p-ISSN : 2087-1333

\title{
GAMBARAN HASIL PEMERIKSAAN HbA 1 C PADA PENDERITA DIABETES MELITUS TIPE II DI RSUD LABUANG BAJI MAKASSAR
}

\author{
Prawansa Amran ${ }^{1}$, Rahman $^{2}$ \\ 1,2 Jurusan Analis Kesehatan Poltekkes Makassar \\ Koresponden : amranprawansa67@gmail.com
}

\begin{abstract}
ABSTRAK
Pemeriksaan $\mathrm{HbA}_{1} \mathrm{C}$ merukapan pemeriksaan yang digunakan untuk mengetahui kadar glukosa darah pada seseorang selama 3 bulan (120 hari) yang telah lalu. Kadar glukosa darah normal pada pemeriksaan ini yaitu 6,3\%, jika kadar glukosanya lebih dari 6,3\% hal tersebut menunjuk bahwa kadar glukosa seseorang tersebut meningkat atau tidak terkontrol. Pemeriksaan ini sangat bermanfaat bagi dokter untuk mengetahui pengobatan lanjutan yang akan diberikan pada pasien, tapi untuk masyarakat awam pemeriksaan ini masih lazim didengar karna pemeriksaan ini tergolong metode pemeriksaan glukosa darah yang baru. Penelitian ini bertujuan untuk mengetahui gambaran glukosa darah pada pasien yang berobat di RSUD Labuang Baji Makassar. Sampel yang digunakan dalam penelitian ini yaitu sebanyak 20 sampel darah yang berbeda. Hasil pemeriksaan sampel-sampel tersebut mengalami peningkatan yang sangat luar biasa, karna sebagian dari sampel tersebut menghasilkan kadar glukosa darah yang tinggi yaitu sekitar $10-13 \%$. Berdasarkan dari hasil penelitian maka dapat disimpulkan bahwa kadar glukosa darah pada pemeriksaan $\mathrm{HbA}_{1} \mathrm{C}$ mengalami peningkatan yang menunjukkan bahwa kadar glukosa darah pasien tersebut tidak terkontrol selama 3 bulan (120 hari) yang lalu.
\end{abstract}

Kata Kunci : $\mathrm{HbA}_{1} \mathrm{C}$, Glukosa darah, sampel darah

\section{PENDAHULUAN}

Diabetes Melitus (DM) merupakan pembunuh nomor empat di dunia, banyak orang tidak mengetahui bahwa mereka menderita diabetes, penyakit diabetes ini terjadi tanpa adanya keluhan sampai beberapa tahun. Penyakit diabetes ini dapat menyerang manusia mulai dari umur 20 tahun, bahkan karena keturunan, dan juga obesitas (kegemukan), inilah faktor utama yang dapat menyebabkan penyakit diabetes. Menurut (WHO) penyakit diabetes di Indonesia menduduki urutan ke tujuh yaitu sebanyak 4,5\% pada tahun (1995).

Diabetes Melitus ( DM ) tipe 2 merupakan suatu kelompok penyakit metabolik dengan karekteristik hiperglikemia yang terjadi karena resistensi insulin, disertai defisiensi insulin relatif. Pemantauan status metabolik pasien DM merupakan hal yang penting. Salah satu metode yang dapat digunakan untuk menentukan pengendalian glukosa darah pada 
Jurnal Media Analis Kesehatan, Vol. 9, No.2, November 2018 http://journal.poltekkes-mks.ac.id/ojs2/index.php/mediaanalis e-ISSN : 2621-9557 p-ISSN : 2087-1333

penderita DM adalah pengukuran Hemoglobin-glikosilat $\quad\left(\mathrm{HbA}_{1} \mathrm{C}\right)$ (Ramadhan dan Marissa, 2015 ).

Diabetes Melitus tidak dapat disembuhkan, tetapi kadar glukosanya dapat dikurangi, dalam pinatalaksanaan dan kontrol diabetes. Bukan hanya glukosa darah yang perlu diperiksa tetapi juga kadar $\mathrm{HbA}_{1} \mathrm{C}$ penting pula untuk diperiksa sebagai pengendalian diabetes yang lebih baik dibandingkan glukosa darah.

Diabetes Melitus (DM) tipe 1 sering dikategorikan seagai kelainan terhadap system imun/kekebalan tubuh. Hal tersebut dikarenakan pada DM tipe 1, sistem kekebalan tubuh merusak sel penghasil hormon insulin yang terdapat dipankreas. DM tipe 1 terjadi saat tubuh kekurangan hormon insulin, sehingga kadar glukosa ( gula darah ) meningkat hingga diatas normal. Penderita DM tipe 1 hanya memproduksi insulin dalam jumlah yang sangat sedikit atau bahkan tidak sama sekali.

Diabetes Melitus (DM) tipe 2 merupakan kelompok DM dengan resistensi insulin disertai defisiensi insulin relatif. Kecurigaan adanya DM perlu mendapatkan perhatian bila ada keluhan klasik DM berupa poliuria, polidipsia, polifagia dan terjadi penurunan berat badan yang tidak dapat dijelaskan sebabnya. DM tipe 2 sering tidak dapat dirasakan gejalanya pada stadium awal dan tetap tidak terdiagnosis dalam waktu lama sampai terjadi berbagai komplikasi (Ramadhan dan Marissa, 2015 ).

Diabetes Melitus (DM) tipe 1 sering dikategorikan seagai kelainan terhadap system imun/kekebalan tubuh. Hal tersebut dikarenakan pada DM tipe 1, sistem kekebalan tubuh merusak sel penghasil hormon insulin yang terdapat dipankreas. DM tipe 1 terjadi saat tubuh kekurangan hormon insulin, sehingga kadar glukosa (gula darah) meningkat hingga diatas normal. Penderita DM tipe 1 hanya memproduksi insulin dalam jumlah yang sangat sedikit atau bahkan tidak sama sekali.

Diabetes Melitus (DM) tipe 2 merupakan kelompok DM dengan resistensi insulin disertai defisiensi insulin relatif. Kecurigaan adanya DM perlu mendapatkan perhatian bila ada keluhan klasik DM berupa poliuria, polidipsia, polifagia dan terjadi penurunan berat badan yang tidak dapat dijelaskan sebabnya. DM tipe 2 sering tidak dapat dirasakan gejalanya pada stadium awal dan tetap tidak terdiagnosis dalam waktu lama sampai terjadi berbagai komplikasi (Ramadhan dan Marissa, 2015 ).

$1 \mathrm{HbA}_{1} \mathrm{C}$ merupakan ikatan molekul glukosa pada hemoglobin secara non-enzimatik melalui proses glikasi post translasi, hemoglobin yang terglikasi terlihat dalam beberapa asam amino $\mathrm{HbA}$ yang terdiri dari $\mathrm{HbA}_{1} \mathrm{a}, \mathrm{HbA}_{1} \mathrm{~b}$, dan $\mathrm{HbA}_{1} \mathrm{C}$. komponen yang terpenting dari glikasi hemoglobin tersebut dalam penyakit $\mathrm{DM}$ adalah $\mathrm{HbA}_{1} \mathrm{C}$, parameter ini digunakan sebagai patokan utama untuk pengendalian penyakit Diabetes Melitus karena $\mathrm{HbA}_{1} \mathrm{C}$ dapat menggambarkan kadar gula darah dalam rentang waktu 1-3 bulan karena usia sel darah merah yang terikat oleh molekul glukosa adalah 120 hari (Ramadhan dan 
Marissa, 2015 ).

Telah dilakukan studi penelitian oleh united kindom prospective Diabetes Mellitus study (UKPDS) mengungkapkan bahwa semakin tinggi nilai $\mathrm{HbA}_{1} \mathrm{C}$ pada penderita DM maka semakin tinggi potensial terjadinya komplikasi pada pasien, kadar $\mathrm{HbA}_{1} \mathrm{C}$ dapat terkontro dengan cara menjaga kestabilan glukosa dalam darah agar tetap normal.

Berdasarkan pada uraian diatas maka peneliti telah melakukan penelitian tentang gambaran hasil pemeriksaan $\mathrm{HbA}_{1} \mathrm{C}$ pada penderita Diabetes Melitus tipe 2.

\section{METODE}

Jenis penelitian ini bersifat deskriptif yang dilakukan secara pendekatan observasi laboratorik, untuk mengetahui hasil pengontrolan pemeriksaan kadar glukosa darah dalam jangka waktu 120 hari sebelumnya (3 bulan sebelum pemeriksaan).

Penelitian ini dilaksanakan di Laboratorium Patologi Klinik RSUD Labuang Baji Makassar pada Juli 2018.

Populasi yang diambil oleh peneliti yaitu pasien penderita Diabetes Melitus tipe 2 yang berobat di RSUD Labuang Baji Makassar. Sedangkan sampel dalam melakukan penelitian ini di ambil sebanyak 20 penderita Diabetes Melitus Tipe 2 dengan metode accidental sampling.

Prosedur Kerja

a. Control Pocket Chem A1c

Membuka tutup botol kontrol dan membuka tutup dari water for reconstitution, menambahkan 6 tetes air reconstitusi ke botol kontrol, lalu tutup kembali botol kontrolnya. Kemudian biarkan 15 menit, lalu goyangkan botol perlahan dan hindari terjadinya Bubbles, dan tunggu hingga 15 menit.

Melarutkan kontrol yang siap digunakan dan pastikan sudah larut, menyiapkan larutan kontrol cartridge, sampel stick, dan palstik tray, lalu scan barcode cartridge, lalu tempatkan cartridge kealat, lalu tekan masuk reagent bead. Goyangkan botol kontrol secara pelan, lalu teteskan ke plastic tray dengan dropper, dan ambillah larutan kontol dengan sampel stick, lalu taruh di cartridge, dan tutup alat, setelah itu hasil Berdasarkan hasil penelitian yang telah dilakukan maka diperoleh hasil sebagai berikut : control akan keluar.

b. Running a test pocket chem A1c

Menyalakan pocket chem A1c, lalu tunggu hingga selesai warning up selama 4 menit, kalibrasi-scan barcode dikotak cartridge. Bukalah dan lepaskan foil dar cartridge, pastikan cartridge mencapai suhu ruangan dan bebas dari embun. Menempatkan cartridge di instrument.

Menekan reagen bead masuk ke cartridge, kemudian siapkan sampel dan mengambil sampel dengan stick, kemudian masukkan sampel stick ke cartridge, lalu tutup pocket chem. A1, setelah itu membaca hasilnya dan mengeluarkan cartridge bekas 
pakai dari alat.

Hasil penelitian disajikan dalam bentuk tabel untuk melihat gambaran hasil pemeriksaan $\mathrm{HbA}_{1} \mathrm{C}$ pada penderita Diabetes Melitus kemudian dibahas secara narasi dan ditarik kesimpulan.

\section{HASIL}

Tabel 1 Gambaran hasil pemeriksaan $\mathrm{HbA}_{1} \mathrm{C}$ pada penderita DM tipe 2 .

\begin{tabular}{ccccc}
\hline No & $\begin{array}{c}\text { Kode } \\
\text { Sampel }\end{array}$ & $\begin{array}{c}\text { Hasil } \\
\text { Pemeriksaan } \\
\text { HbA1C\% }\end{array}$ & $\begin{array}{c}\text { Kadar } \\
\text { Glukosa } \\
\text { (mg/dl) }\end{array}$ & Ket \\
\hline $\mathbf{1}$ & $\mathrm{A} 1$ & $12.6 \%$ & 342 & $\mathrm{TN}$ \\
\hline $\mathbf{2}$ & $\mathrm{A} 2$ & $11.5 \%$ & 330 & $\mathrm{TN}$ \\
\hline $\mathbf{3}$ & $\mathrm{A} 3$ & $12.0 \%$ & 340 & $\mathrm{TN}$ \\
\hline $\mathbf{4}$ & $\mathrm{A} 4$ & $10.0 \%$ & 289 & $\mathrm{TN}$ \\
\hline $\mathbf{5}$ & $\mathrm{A} 5$ & $7.3 \%$ & 210 & $\mathrm{TN}$ \\
\hline $\mathbf{6}$ & $\mathrm{B} 6$ & $6.8 \%$ & 182 & $\mathrm{TN}$ \\
\hline $\mathbf{7}$ & $\mathrm{B} 7$ & $11.3 \%$ & 310 & $\mathrm{TN}$ \\
\hline $\mathbf{8}$ & $\mathrm{B} 8$ & $8.9 \%$ & 284 & $\mathrm{TN}$ \\
\hline $\mathbf{9}$ & $\mathrm{B} 9$ & $5.7 \%$ & 105 & $\mathrm{~N}$ \\
\hline $\mathbf{1 0}$ & $\mathrm{B} 10$ & $5.4 \%$ & 102 & $\mathrm{~N}$ \\
\hline $\mathbf{1 1}$ & $\mathrm{C} 11$ & $5.6 \%$ & 103 & $\mathrm{~N}$ \\
\hline $\mathbf{1 2}$ & $\mathrm{C} 12$ & $8.3 \%$ & 273 & $\mathrm{TN}$ \\
\hline $\mathbf{1 3}$ & $\mathrm{C} 13$ & $4.5 \%$ & 80 & $\mathrm{~N}$ \\
\hline $\mathbf{1 4}$ & $\mathrm{C} 14$ & $5.1 \%$ & 83 & $\mathrm{~N}$ \\
\hline $\mathbf{1 5}$ & $\mathrm{C} 15$ & $5.3 \%$ & 90 & $\mathrm{~N}$ \\
\hline $\mathbf{1 6}$ & $\mathrm{D} 16$ & $8.3 \%$ & 275 & $\mathrm{TN}$ \\
\hline $\mathbf{1 7}$ & $\mathrm{D} 17$ & $5.6 \%$ & 105 & $\mathrm{~N}$ \\
\hline $\mathbf{1 8}$ & $\mathrm{D} 18$ & $5.4 \%$ & 104 & $\mathrm{~N}$ \\
\hline $\mathbf{1 9}$ & $\mathrm{D} 19$ & $5.2 \%$ & 85 & $\mathrm{~N}$ \\
\hline $\mathbf{2 0}$ & $\mathrm{D} 20$ & $13.8 \%$ & 360 & $\mathrm{TN}$ \\
\hline
\end{tabular}

Sumber : Data primer berdasarkan penelitin pada Bulan 2018

Pada penelitian ini di lakukan pemeriksaan sebanyak 20 sampel yang berasal dari RSUD Labuang Baji Makassar. Pengambilan sampel dilaksanakan pada tanggal 20 Juni - 31 Juli 2018. Pada table 1 data hasil pemeriksaan $\mathrm{HbA} 1 \mathrm{C}$ dan kadar glukosa

Pada penelitian ini didapatkan batas normal pemeriksaan $\mathrm{HbA}_{1} \mathrm{C}$ yaitu 6.3 $\% \quad(140 \mathrm{mg} / \mathrm{dl})$ Sedangkan angka tertinggi dari pemeriksaan ini yaitu 15,0-16.0 \% (550-600 mg/dl). Subjek penelitian yang memiliki hasil tidak normal yaitu sebanyak 11 orang pasien $(6,8 \%$ - 13,8\%), dimana pasien yang kadar $\mathrm{HbA}_{1} \mathrm{C}$ nya yaitu $12,6 \%$ menunjukkan bahwa kadar glukosa darahnya sebanyak $342 \mathrm{mg} / \mathrm{dl}$ dan yang hasil pemeriksaan $\mathrm{HbA}_{1} \mathrm{C}$ nya $6,8 \%$ menandakan kadar glukosa darahnya yaitu $182 \mathrm{mg} / \mathrm{dl}$, dan yang memiliki 
hasil normal yaitu sebanyak 9 orang pasien $(4,5 \%-5,7 \%)$ dimana jika kadar $\mathrm{HbA}_{1} \mathrm{C}$ nya 5,7 \% $105 \mathrm{mg} / \mathrm{dl}$ sedangkan yang kadar $\mathrm{HbA}_{1} \mathrm{C}$ nya $4,5 \%$ kadar glukosa darahnya sekitar $80 \mathrm{mg} / \mathrm{dl}$. Hal ini menunjukkan bahwa kadar glukosa pada pemeriksaan $\mathrm{HbA}_{1} \mathrm{C}$ banyak yang mengalami peningkatan akibat kurang terkontrolnya pola makan pada pasien.

\section{PEMBAHASAN}

Berdasarkan hasil penelitian yang dilakukan di RSUD Labuang Baji Makassar khususnya dilabolatorium patologi klinik pada tanggal 20 junii s/d 31 Juli 2016 dengan jumlah sampel penderita Diabetes Melitus tipe 2 sebanyak dua puluh (20) sampel.

Hemoglobin $\mathrm{A}_{1} \mathrm{c}$ atau $\mathrm{HbA}_{1} \mathrm{C}$ adalah komponen minor dari hemoglobin yang berkaitan dengan glukosa, $\mathrm{HbA}_{1} \mathrm{C}$ juga kadag-kadang disebut sebagai glikosilasi atau hemoglobin glikosilasi atau pada pasien diabetes, dimana pemeriksaan ini juga berfungsi sebagai indikator jangka panjang kontrol glukosa darah, bisa juga digunakan untuk memonitor efek dapat digunakan untuk memantau kadar glukosa darah per hari atau tes rutin gula darah.

Parameter $\mathrm{HbA}_{1} \mathrm{C}$ umumnya digunakan sebagai penanda untuk penilaian kontrol glikemik yang digunakan secara rutin dalam menejemen diabetes. $\mathrm{HbA}_{1} \mathrm{C}$ merupakan ikatan molekul glukosa pada hemoglobin.

secara non-enzimatik melalui proses glikasi post translasi, hemoglobin yang terglikasi terlihat dalam beberapa asam amino $\mathrm{HbA}$ yang terdiri dari $\mathrm{HbA}_{1} \mathrm{a}$, $\mathrm{HbA}_{1}$ b, $\mathrm{HbA}_{1} \mathrm{C}$. $\mathrm{HbA}_{1} \mathrm{C}$ merupakan salah satu pemeriksaan yang dapat membantu dalam menegakkan diagnosis, pemeriksaan $\mathrm{HbA}_{1} \mathrm{C}$ ini dapat memudahkan dokter untuk mengetahui kontrol glukosa pada pasien.

Diabetes Melitus (DM) tipe 2 merupakan kelompok DM dengan resistensi insulin disertai defisiensi insulin relatif. Kecurigaan adanya DM perlu mendapatkan perhatian bila ada keluhan klasik DM berupa poliuria, polidipsia, polifagia dan terjadi penurunan berat badan yang tidak dapat dijelaskan sebabnya. DM tipe 2 sering tidak dapat dirasakan gejalanya pada stadium awal dan tetap tidak terdiagnosis dalam waktu lama sampai terjadi berbagaikomplikasi Menurut WHO pemeriksaan $\mathrm{HbA}_{1} \mathrm{C}$ dapat digolongkan beberapa kategori yaitu sebagai berikut :

Tabel 1. Pembagian kategori $\mathrm{HbA}_{1} \mathrm{C}$

\begin{tabular}{ccc}
\hline No & Kadar HbA H $_{1}$ & Keterangan \\
\hline $\mathbf{1}$ & $\mathrm{HbA}_{1} \mathrm{C}<6.5 \%$ & $\begin{array}{c}\text { Kontrol Glikemiknya } \\
\text { Baik }\end{array}$ \\
\hline $\mathbf{2}$ & $\mathrm{HbA}_{1} \mathrm{C} 6.5-8 \%$ & $\begin{array}{c}\text { Kontrol Glikemik } \\
\text { Normal }\end{array}$ \\
\hline $\mathbf{3}$ & $\mathrm{HbA}_{1} \mathrm{C}>8 \%$ & Kontrol Glikemik Buruk \\
\hline
\end{tabular}


Jurnal Media Analis Kesehatan, Vol. 9, No.2, November 2018

http://journal.poltekkes-mks.ac.id/ojs2/index.php/mediaanalis

e-ISSN : 2621-9557

p-ISSN : 2087-1333

Nilai normal pemeriksaan $\mathrm{HbA}_{1} \mathrm{C}$ berdasarkan umur dan jenis kelamin yaitu sebagai berikut :

Tabel 2 Pembagian $\mathrm{HbA}_{1} \mathrm{C}$ berdasarkan umur

\begin{tabular}{cccc}
\hline No & Umur & $\begin{array}{c}\text { Laki - } \\
\text { Laki }\end{array}$ & Perempuan \\
\hline 1 & $5-24$ tahun & $5,02 \%$ & $4.95 \%$ \\
\hline 2 & $40-45$ tahun & $5.02 \%$ & $4.1 \%$ \\
\hline
\end{tabular}

Pada pemeriksaan $\mathrm{HbA}_{1} \mathrm{C}$ dapat digolongkan menjadi tiga bagian pasien tanpa diabetes yaitu $3.5 \%-5.0 \%$, pasien pradiabetes yaitu antara $5.7 \%$ $6.4 \%$, dan penderita diabetes melitus yaitu diatas $6.5 \%$. Pada hasil penelitian ini menunjukkan bahwa hasil pemeriksaan kadar glukosa darah pada pasien-pasien tersebut banyak yang mengalami peningkatan atau melebihi batas normal, dimana hal ini menunjukkan bahwa banyaknya pasien-pasien diabetes yang tidak dapat mengontrol dengan baik kadar glukosa darahnya selama 3 bulan (120 hari) yang lalu.

Hal ini dapat terjadi karna kurangnya pemahaman dan kesadaran pada diri pasien akan makanan dan halhal yang perlu mereka perhatikan agar kadar glukosa darah mereka tetap terkontrol dengan baik. Namun adapun beberapa pasien yang kadar glukosa darahnya normal hal ini dapat terjadi karena kesadaran pasien tersebut dengan makanan dan pola hidup sehat yang mereka lakukan, dimana kadar glukosa darah pasien tersebut selama 3 bulan (120 hari) yang lalu tetap terkontrol dengan baik, dengan

\section{DAFTAR PUSTAKA}

Brudenell M, Doddridge MC, 1994. melakukan pola hidup sehat, olahraga dan pengontrolan kadar glukosa darah setiap bulannya, seperti pemeiksaan gula darah puasa (GDP), gula darah sewaktu (GDS) dan pemeriksaan Tes Toleransi Glukosa (TTG) dan banyak lagi.

\section{KESIMPULAN}

Dari hasil penelitian ini dapat disimpulkan bahwa kadar glukosa darah pada pasien-pasien yang berkunjung ke labolatorium patologi klinik RSUD tersebut mengalami peningkatan yaitu $12.0 \%$ atau setara dengan $300 \mathrm{mg} / \mathrm{dl}$ dan nilai normalnya yaitu $5.0 \%$ atau setara dengan 100 $\mathrm{mg} / \mathrm{dl}$.

\section{SARAN}

1. Kepada masyarakat agar selalu menerapkan pola hidup sehat setiap harinya.

2. Kepada peneliti agar dapat melanjutkan penelitian ini ke jenjang yang lebih spesifik seperti analisis glycated albumin dan glycated hemoglobin $\left(\mathrm{HbA}_{1} \mathrm{C}\right)$ pada penderita diabetes melitus tipe 2 .

Diabetes Pada Kehamilan, Penerbit Buku Kedokteran EGC 
Bloom,A. 1990. DIABETES. Dian Karya: Jakarta

Epidemologi DM, 2016. http://www.Mediskus.com diunduh tanggal 15 juli 2016.

$\mathrm{HbA}_{1}$ c. 2016. http://www.abclab.co.id diunduh tanggal 13 mei 2016.

Hermani N. 2002. Kadar Glukosa Darah Pada Penderita Gizi Buruk, Tesis. Program Pasca Sarjana Universitas Hasanuddin Makassar.

Leslie,R.D.G.1995. Buku Pintar Kesehatan DIABETES. Surya satyanegara:Jakarta.

Mistra. 2004. 3 jurus melawan Diabetes Melitus.Puspa Sehat:Jakarta.

Perkeni. Konsensus pengelolaan dan pencegahan diabetes melitus tipe 2 di Indonesia. Jakarta:PB Perkeni 2011 p.31,38.

Ranakusuma. 1982. Penyakit Kencing Manis DIABETES MELITUS. Universitas Indonesia:Jakarta

Ramadhan, Nur dan Marissa, Nelly. 2015.Karakteristik penderita diabetes melitus tipe 2 berdasarkan kadar HbAlc dipuskesmas jayabaru kota Banda Aceh (Online) (http://mediskus.com/dasar/ pengertian-hbalc-pemeriksaandan-nilai-normal, diunduh 26 maret 2016).

Sri, Dewanti. 2005. Kolestrol Diabetes Dan Asam Urat, Gramedia Pustaka Utama.

Tandra,Hans. 2008. Segala sesuatu yang harus anda ketahui tentang DIABETES. PT Gramedia Pustaka Utama: Jakarta 